\title{
Impact of Parenting Styles on Psychological Flexibility Among Adolescents of Pakistan: A Cross-Sectional Study
}

\author{
Akhtar Bibi $^{1} \cdot$ Raheela Hayat $^{2} \cdot$ Nadia Hayat $^{2} \cdot$ Sadia Zulfiqar $^{3} \cdot$ Nadia Shafique $^{4} \cdot$ Muhammad Adnan Khalid $^{5}$
}

Accepted: 20 February 2021 / Published online: 10 March 2021

(c) The Author(s) 2021

\begin{abstract}
The parenting styles and psychological flexibility have been significant variables; however, little empirical work has addressed the impact of parenting in terms of the expansion of psychological flexibility. The present study investigated the impact of different parenting styles as a predictor of psychological flexibility in the adolescent population. A total sample of 100 adolescents ( 50 boys and 50 girls) whose ages ranged between 12 and 18 years without any previous psychiatric and medical history were recruited from different educational institutes of Pakistan. Results revealed that parenting styles are positively associated with psychological flexibility $(r=0.75, p<0.05)$. Moreover, parenting styles significantly predict psychological flexibility among adolescents $(p<0.05)$. However, no gender differences were found across both variables among adolescents. These findings have highlighted the significance of parenting styles and psychological flexibility with respect to the mental health of adolescents.
\end{abstract}

Keywords Parenting Styles $\cdot$ Psychological Flexibility $\cdot$ Adolescents $\cdot$ Gender differences $\cdot$ Pakistan

Akhtar Bibi

Akhtar.Bibi@ruhr-uni-bochum.de

Raheela Hayat

Raheela_hayat786@yahoo.com

Nadia Hayat

Nadiahayat990@yahoo.com

Sadia Zulfiqar

sadiazulfiqar04@gmail.com

Nadia Shafique

nadiashafique17@gmail.com

Muhammad Adnan Khalid

adnankhalid4080@gmail.com

1 Mental Health Research and Treatment Center, Faculty of Psychology, Ruhr-Universität Bochum, Massenbergstraße 9-13, 44787 Bochum, Germany

2 Department of Psychology, National University of Modern Languages, Islamabad, Pakistan

3 National Institute of Psychology, Quaid-i-Azam University, Islamabad, Pakistan

4 Department of Psychology, Foundation University, Rawalpindi, Pakistan

5 Institute for Sport Sciences and Psychology, Westfälische Wilhelms-Universitat, Munster, Germany
Existent literature shows that among a wide range of influences on the development of child, parenting is the most influential factor which determines the childhood psychopathology and child's development. Parenting styles means attitudes and behaviors that parents generally use across different contexts to manage the behavior of their children by exerting affection, receptiveness, control, and punishment. In successful parenting, numerous biological and environmental factors also play major role in determining, whether the child will be able to respond accurately to the internal experiences and environmental demands to achieve their goal, i.e., establishing their psychologically flexibility. Parents hold special importance during the early years of their children's lives. They acts as a guide for their children for experiencing the initial stages of autonomy from the stages of absolute infantile reliance. Their parenting styles could have direct or indirect effects on social, moral and academic development of their children. Parents are required to deal with the challenge of balancing the maturity and disciplinary demands they make to integrate children into family and social system, while keeping an atmosphere of receptiveness and warmth for ensuring the best possible outcome for their children. Children may experience a multitude of adjustment problems when there is an imbalance in provision of care and disciplinary controls from their parents. Therefore, this 
study is intended to explore the impact of different parenting styles in the growth of psychological flexibility.

Earlier psychopathologies such as internalizing and externalizing issues have been associated with parenting practices (Davidov \& Grusec, 2006; Rodriguez, 2003) and psychological flexibility (Kashdan et al. 2006; Lee et al., 2010). Higher levels of psychological flexibility help in coping with psychological difficulties through acceptance and promotion of desirable behaviors (Fledderus et al., 2010). Parenting styles refer to the pattern of parental behaviors and approaches towards their children and a passionate environment in which parents rear their children (Darling \& Steinberg, 1993). There are different parenting styles: parent's control includes restrictive, nursing, and modifying the behavior of the child, while a parent's warmth involves acceptance and love. Darling and Steinberg (1993) made a distinction between parenting styles and parenting practices by referring parenting styles as a parent-child interaction across situations and settings whereas parenting practices are specific to certain situations and domains. Currently, the three parenting styles, i.e., authoritarian, authoritative, and permissive, introduced by Baumrind (1971) are extensively used models of parenting styles. Authoritarian parenting style is represented by a lower level of affection, high control, strict discipline, and unresponsiveness towards the emotional requirements of children (Chipman et al., 2000). While authoritative parenting is represented by higher warmth, control, and responsiveness and is linked with a higher level of self-control and independence in children (Coolahan et al., 2002). Lastly, permissive parenting is characterized by low warmth, control, and expectations, which causes poor self-regulation among children (Chipman et al., 2000). Authoritative parenting refers to the higherlevel warmth as well as control and have been found the most effective parenting style (Darling \&Toyokawa, 1997).

Psychological flexibility is characterized by the individual's ability to react appropriately to different circumstances and emotional demands in order to achieve one's goals (Kashdan, \& Rottenberg, 2010; Landstra et al., 2013). For instance, an individual is supposed to respond immediately and appropriately to unexpected and normal situations. Kashdan and Rottenberg's (2010) defined psychological flexibility in terms of self-control, self-regulation, and emotional regulation (Moilanen et al., 2010). These characteristics are associated with psychological capability, which adolescents need to attain their objective in a complex social setting (Haugstvedt, Wentzel-Larsen, Rokne, \& Graue, 2011). According to Hayes et al. (2011), there are six distinctive elements of psychological flexibility: Acceptance (shows readiness to interact with undesirable experiences entirely), Contact with the Present Moment (awareness of one's experience), Self as Context (to keep the view of oneself within one's understanding), Defusion (to deal with undesirable experiences without getting trapped in them), Committed Action (sustaining attitudes for significant parts of life), and Values (remain linked with course life and direct the behaviors) (Rolffs et al., 2018).

Recently, there has been a growing interest in examining the association between psychological flexibility, psychological, and social consequences (Brassell et al., 2016). Higher psychological flexibility is linked with positive consequences such as adaptive psychological functioning, higher emotional wellbeing, and quality of life (Bond \& Bunce, 2003; Hayes et al., 2006). Contrary, lower psychological flexibility is linked with higher psychopathologies (Tull et al., 2004) and emotional responses (Sloan, 2004). Psychological flexibility is greatly influenced by parenting style (Haugstvedt, Wentzel-Larsen, Rokne, \& Graue, 2011; Williams et al., 2012) and the context in which children are raised. However, it is still uncertain how parenting is related to the development of psychological flexibility. Parents spend their time, energies and resources to raise their children (Trivers \& Willard, 1973), however, it is unclear whether behavior is influential (Moilanen et al., 2010), or amalgamation of both parental control and warmth is advantageous during late adolescence and early adulthood (Liem et al., 2010). Even though, not a single theory of parenting is comprehensive and absolute, clearly explaining how it shapes the development of children. But still, there is enough evidence supporting that the child's development is significantly influenced by the parenting styles (Thergaonkar \& Wadkar, 2007).

With respect to mental health issues, parenting is major factor promoting psychological flexibility among adolescents (Flujas-Contreras, \& Gómez, 2018). Alegre (2011) reported in a review study that parenting is associated with several psychological constructs such as emotional intelligence and psychological flexibility (Bhattacharyya, \& Pradhan, 2015; Brand et al., 2009). Moreover, evidence from past studies indicated that parenting styles influence the adolescent's self-motivation, self-esteem, and stress cognition (Huver et al., 2007). The adolescents with authoritative parents have a higher level of self-esteem and self-regulation (Milevsky et al., 2007), while parent's authoritarian styles are inversely associated with self-conception and confidence (Chan \& Koo, 2011). Moreover, adolescents with authoritative fathers are more determined and persistent regardless of resistances, interruptions, and internal causes of motivations (Padilla-Walker, Day, Dyer \& Black, 2013).

In addition, parental practices have been found associated with emotional regulation, adaptability, and impulsiveness (Barros et al., 2015). Parental emotional control impacts the children understanding of emotions and behaviors (Gugliandolo et al., 2014). Adolescents with authoritative parents studying in high schools reported a higher ability to attain their objectives (psychological flexibility) 
with respect to the environmental demands (Williams et al., 2012). In comparison, adolescents with authoritarian parents indicated lower levels of psychological flexibility. Supportive and responsive parenting have also been associated with empathetic behaviors in the adolescent samples (Laible \& Carlo, 2004). Previously, numerous studies have examined the association between these two variables in Western countries (Moyer, \& Sandoz, 2015; Williams et al., 2012). But to the best knowledge of researcher, the association between these constructs and gender differences has not still studied in Pakistan, specifically in the adolescent population who experience a higher number of psychological difficulties due to the growing and demanding age (Bibi, Blackwell \& Margraf, 2019; Bibi, Lin, Zhang \& Margraf, 2020).

Socio-cultural factors and socialization practices also impact parenting approaches. Parents encourage autonomy, self-reliance, competitiveness, and self-expression in Western cultures (Keller \& Otto, 2009), while parents in Asian culture normally have authoritarian parenting styles to control and shape the behavior of the child (Mousavi, Low, and Hashim, 2016), therefore, it is important to contemplate the cultural context. This study aimed to fill this gap by advancing the present literature related to parenting practices and psychological flexibility of Pakistani adolescent population.

Similarly, gender differences in psychological flexibility (Azevedo \& Matos, 2015) and parenting styles in terms of mental health have been rarely investigated. Therefore, it would be noteworthy to examine gender differences in perceived parenting styles and psychological flexibility in the socio-cultural context of Pakistan, where adolescent girls are encouraged to spend their time at home, whereas boys are encouraged to stay outside and involve in social activities. Barnhart et al. (2013) explained that fathers are considered as authoritarian and mothers are considered as more authoritative and occasionally more permissive in Asian cultures. However, the parenting practices are transforming in recent years and fathers are equally getting involved in the parenting practices (Bhattacharyya \& Pradhan, 2015). In Asian culture, boys and girls have different social roles, therefore parenting vary for both genders. In the culture of Pakistan, girls are expected to be more passive, dependent and submissive with respect to their gender roles (Bibi et al., 2018), while boys are expected be aggressive, dominant and independent. However, parenting practices are changing with time due to increased industrialization, modernization, awareness, and financial progress. Likewise, expectations and needs of children are also changing with the passage of time. Therefore, the current study also intended to explore role of gender in association between parenting styles and psychological flexibility.

Keeping in view of the aims of the study, it was hypothesized that:
1. Parenting styles such as permissive parenting style, authoritarian parenting style, authoritative parenting style will significantly predict multidimensionally psychological flexibility such as acceptance, present moment awareness, self as context, defusion, values, committed action among adolescents.

2. Authoritative and permissive parenting styles would be positively, and Authoritarian parenting style would be negatively associated with psychological flexibility.

3. Gender would moderate the relationship between parenting styles and psychological flexibility among adolescents.

\section{Method}

\section{Participants}

This study employed a cross-sectional study design. Convenient purposive sampling technique was applied to collect the data from 50 males and 50 females having a mean age of $(M=15.35)$ and standard deviation $(S D=1.76)$ from different educational institutes. Inclusion criteria included obtaining informed consent and including adolescents with ages ranging between 12 to 18 years with no previous psychiatric or medical history. English versions of all the questionnaires were used as English is the official language of Pakistan. Moreover, the medium of instruction in educational institution is also English in Pakistan. Participants took 25 min to complete the survey. The participant's demographic characteristics are presented in Table 1.

Table 1 Demographic characteristics of adolescents $(N=100)$

\begin{tabular}{llll}
\hline $\begin{array}{l}\text { Description of charac- } \\
\text { teristics }\end{array}$ & Categories & Frequency & $\begin{array}{l}\text { Frequency } \\
\text { percentage } \\
(\%)\end{array}$ \\
\hline Age & 12-14 years & 35 & 30.7 \\
& 15-17 years & 48 & 42.1 \\
& Above 18 years & & 31.3 \\
Gender & Male & 50 & 43.9 \\
Education & Female & 50 & 43.9 \\
& Matric & 41 & 3.16 \\
& Intermediate & 59 & 51.8 \\
Socioeconomic status & Missing & 14 & 12.3 \\
& Upper class & 27 & 23.7 \\
& Middle Class & 45 & 39.5 \\
& Lower Class & 28 & 24.0 \\
\hline
\end{tabular}

This table shows the demographic characteristics of adolescents 


\section{Instruments}

\section{Demographic Data}

Demographic data of participants was collected in terms of age, gender, educational level, and socioeconomic status.

The Parental Authoritative Questionnaire (PAQ)

The PAQ was developed by Buri (1991) to measure the parenting styles from the perspective of adolescents. It consists of 30 items and three subscales such as Permissive (e.g., 1, While I was growing up my mother felt that in a well-run home the children should have their way in the family as often as the parents do; items 1, 6, 10, 13, 14, 17, 19, 21, 24 and 28), Authoritarian (e.g., 2. Even if her children didn't agree with her, my mother felt that it was for our own good if we were forced to conform to what she thought was right; items 2, 3,7, 9, 12, 16, 18, 25, 26 and 29), and Authoritative/flexible (e.g., As I was growing up, once family policy had been established, my mother discussed the reasoning behind the policy with the children in the family; items 4, 5, 8, 11, 15, 20, 22,23, 27, and 30). Participant responded on these items on a five-point Likert scale ranging from 1 (strongly disagree) to 5 (strongly agree). Scores on each subscale ranged from 10 to 50 . High scores on each subscale indicate a higher perception of the presence of the parental prototype measured. Cronbach's alpha reliability coefficients for all the subscales were reported above 0.77 (Buri, 1991). In our sample, Cronbach alpha of PAQ was 0.87 (Excellent).

\section{The Multidimensional Psychological Flexibility Inventory (MPFI)}

MPFI developed by Rolffs et al., (2016) was used to assess the different dimensions of the psychological flexibility of participants. It consists of 60 items and twelve subscales. The first six subscales measure psychological flexibility, and the next six subscales measure psychological inflexibility. Only, first six subscales measuring psychological flexibility were employed in the current study. The subscale are as follows: Acceptance (e.g., "I was receptive to observing unpleasant thoughts and feelings without interfering with them."), Present Moment Awareness(e.g., "I was attentive and aware of my emotions"), Self as context (e.g., "Even when I felt hurt or upset, I tried to maintain a broader perspective"), Defusion (e.g., "I was able to let negative feelings come and go without getting caught up in them"), Values (e.g., "I was very in touch with what is important to me and my life"), Committed Action (e.g., "Even when I stumbled in my efforts, I didn't quit working toward what is important"). Participants responded on a 6-point Likert scale ranging from 1 (never true) to 6 (always true). Higher scores on each subscale show a higher level of the specific dimension being evaluated. In our sample, the Cronbach alpha of MPFI was 0.88 (Excellent).

\section{Procedure}

The current study was ethically approved by the National University of Modern languages, Islamabad. After ethical approval, permission was taken from the respective higher authorities of the educational institutions for data collection. Data was collected from the different institutions that were in easy approach of the researcher. After obtaining permission, participants were approached in their classrooms. They were briefed about the study and their ethical rights. They were instructed to approach the researcher in case of any ambiguity while completing the questionnaires. Then, participants were presented with the questionnaire and were guided about the instruction of the questionnaire. Participants completed the questionnaire in $20-25 \mathrm{~min}$. In the end, participants were thanked for their participation.

\section{Data Analysis}

Statistical Package for Social Sciences (SPSS) version 25 was used to analyze the data of the present study. Descriptive statistics were obtained for all of the study variables. Spearman's Rank-order correlation was applied to study the link between parenting styles and psychological flexibility. Multiple regression analysis was applied to predict psychological flexibility. Moderation analysis was done through Process Macro to investigate the effect of gender on parenting style and psychological flexibility among adolescents. All variables which were included in linear Regression were continuous except the sociodemographic variable such as Gender. It was coded as 1 for males and 2 for females in moderation analysis. Moreover, the robustness of the analyses with respect to collinearity was checked through the examination of Tolerance/Variance Inflation Factors and Cook's D values with the help of statistician (Clark-Carter, 2018).

\section{Results}

\section{Descriptive Analysis}

The values of skewness and kurtosis were within cutoff criteria, indicating the normal distribution of variables. Internal consistency of parenting styles and psychological flexibility was satisfactory (Except the reliability of subscale of psychological flexibility was lower ranging from 0.22 to 0.46 ). Mean, standard deviation, minimum, maximum, kurtosis, and skewness of both variables are presented in Table 2 . 
Table 2 Descriptive statistics of study variables

\begin{tabular}{llrllllrr}
\hline Variables & M & SD & N & A & Range & Actual potential & Skewness & Kurtosis \\
\hline Parental authority questionnaire & 89.32 & 16.55 & 30 & 0.87 & $1-5$ & $30-150$ & 0.220 & 1.096 \\
Permissive parenting style & 29.67 & 6.71 & 10 & 0.78 & $1-5$ & $10-50$ & 0.136 & -0.550 \\
Authoritarian parenting style & 29.90 & 7.01 & 10 & 0.61 & $1-5$ & $10-50$ & 0.009 & -0.359 \\
Authoritative parenting style & 29.75 & 6.96 & 10 & 0.76 & $1-5$ & $10-50$ & 0.220 & 0.201 \\
MPFI & 89.05 & 16.86 & 30 & 0.88 & $1-6$ & $30-180$ & 0.211 & 0.734 \\
Acceptance & 14.50 & 3.59 & 5 & 0.31 & $1-6$ & $5-30$ & 0.183 & -0.834 \\
Present moment awareness & 15.07 & 3.27 & 5 & 0.23 & $1-6$ & $5-30$ & -0.127 & -0.135 \\
Self as context & 14.74 & 3.12 & 5 & 0.24 & $1-6$ & $5-30$ & 0.302 & 0.633 \\
Defusion & 14.74 & 3.50 & 5 & 0.22 & $1-6$ & $5-30$ & 0.109 & -0.380 \\
Values & 15.01 & 3.64 & 5 & 0.31 & $1-6$ & $5-30$ & 0.196 & -0.853 \\
Committed Actions & 14.99 & 4.21 & 5 & 0.46 & $1-6$ & $5-30$ & -0.330 & -0.466 \\
\hline
\end{tabular}

$N=100$

\section{Correlations}

Correlation between composite scores of parenting style and multidimensional psychological flexibility was computed. Results indicated that parenting styles are positively associated with psychological flexibility $(r=0.75,(2,98) p<0.01)$ (see Table 3).

\section{Regression Analysis}

Multiple regression analysis of psychological flexibility with composite scores as well as subscales such as Acceptance, Present Moment, Self as Content, Defusion, Values, Committed Actions as dependent variables and parenting styles such as Permissive, Authoritarian and Authoritative parenting style as independent variables showed significant results
$\left(R^{2}=0.63, F(3,96)=56.61, p<0.001\right)$, (see Table 4). The value of R-Square shows that $63 \%$ of variance in dependent variable (psychological flexibility) can be predicted from the independent variable (parenting styles).

Result indicated that permissive parenting style predicted significantly subscale of psychological flexibility such as Acceptance $\left(R^{2}=0.53, F(3,96)=36.79, p<0.001\right)$, Present Moment $\left(R^{2}=0.53, F(3,96)=36.08, p<0.001\right)$, Self as Content $\left(R^{2}=0.554, F(3,96)=39.79, p<0.001\right)$, Defusion $\left(R^{2}=0.47, F(3,96)=28.59, p<0.001\right)$, Values $\left(R^{2}=0.467\right.$, $F(3,96)=28.01, p<0.001)$, Committed Actions $\left(R^{2}=0.24\right.$, $F(3,96)=10.12, p<0.001)$, whereas authoritative parenting style predicted significantly Self as Content and Defusion. Moreover, Authoritarian parenting style also predicted acceptance subscale of psychological flexibility among the adolescent sample.

Table 3 Correlation between parenting styles and psychological flexibility

\begin{tabular}{|c|c|c|c|c|c|c|c|c|c|c|c|}
\hline Variables & PAQ & PPS & ATPS & APS & MPFI & A & PMA & SAC & $\mathrm{D}$ & V & CA \\
\hline PAQ & _ & $0.668 * *$ & $0.883^{* *}$ & $0.844 * *$ & $0.753 * *$ & $0.700^{* *}$ & $0.623 * *$ & $0.738 * *$ & $0.681 * *$ & $0.528 * *$ & $0.368 * *$ \\
\hline PPS & & _ & $0.360 * *$ & $0.264 * *$ & $0.701 * *$ & $0.553 * *$ & $0.695^{* *}$ & $0.518 * *$ & $0.438 * *$ & $0.673^{* *}$ & $0.466 * *$ \\
\hline ATPS & & & - & $0.747 * *$ & $0.595^{* *}$ & $0.646^{* *}$ & $0.449 * *$ & $0.611 * *$ & $0.578 * *$ & $0.313^{*}$ & $0.280 * *$ \\
\hline APS & & & & - & $0.517 * *$ & $0.482 * *$ & $0.358 * *$ & $0.641 * *$ & $0.614 * *$ & $0.292 * *$ & 0.143 \\
\hline MPFI & & & & & - & $0.751 * *$ & $0.774 * *$ & $0.825^{* *}$ & $0.750 * *$ & $0.840 * *$ & $0.803 * *$ \\
\hline $\mathrm{A}$ & & & & & & _ & $0.421 * *$ & $0.527 * *$ & $0.571 * *$ & $0.630 * *$ & $0.419 * *$ \\
\hline PMA & & & & & & & - & $0.651 * *$ & $0.432 * *$ & $0.674 * *$ & $0.540 * *$ \\
\hline SAC & & & & & & & & - & $0.615^{* *}$ & $0.600 * *$ & $0.576^{* *}$ \\
\hline $\mathrm{D}$ & & & & & & & & & - & $0.412 * *$ & $0.538 * *$ \\
\hline V & & & & & & & & & & - & $0.653 * *$ \\
\hline CA & & & & & & & & & & & - \\
\hline
\end{tabular}

$N=100$

PAQ Parental Authority Questionnaire, PPS Permissive Parenting Style, ATPS Authoritarian Parenting Style, APS Authoritative Parenting Style, MPFI Multidimensional Psychological Flexibility Inventory, A Acceptance, PMA Present Moment Awareness, SAC Self as Context, D Defusion, $V$ Values, $C A$ Committed Action

$* * \mathrm{p}<.01$ 
Table 4 Multiple regression analysis with parenting styles such as permissive, authoritarian and authoritative parenting style as an independent variables and present moment, self as content, defusion, values, committed actions as dependent variables

\begin{tabular}{|c|c|c|c|c|c|}
\hline & $R^{2}$ & $B$ & $S E$ & $95 \% C L$ & $P$ \\
\hline $\begin{array}{l}\text { Psychological flexi- } \\
\text { bilty }\end{array}$ & 0.639 & & & & \\
\hline $\begin{array}{l}\text { Permissive parent- } \\
\text { ing }\end{array}$ & & 0.560 & 0.165 & $1.080,1.736$ & 0.000 \\
\hline $\begin{array}{l}\text { Authoritarian par- } \\
\text { enting }\end{array}$ & & 0.266 & 0.229 & $0.184,1.095$ & 0.006 \\
\hline $\begin{array}{l}\text { Authoritative par- } \\
\text { enting }\end{array}$ & & 0.171 & 0.223 & $-0.029,0.857$ & 0.067 \\
\hline Acceptance & 0.535 & & & & \\
\hline $\begin{array}{l}\text { Permissive parent- } \\
\text { ing }\end{array}$ & & 0.368 & 0.040 & $0.118,0.276$ & 0.000 \\
\hline $\begin{array}{l}\text { Authoritarian par- } \\
\text { enting }\end{array}$ & & 0.511 & 0.055 & $0.152,0.372$ & 0.000 \\
\hline $\begin{array}{l}\text { Authoritative par- } \\
\text { enting }\end{array}$ & & 0.003 & 0.054 & $-0.106, .109$ & 0.978 \\
\hline $\begin{array}{l}\text { Present moment } \\
\text { awareness }\end{array}$ & 0.530 & & & & \\
\hline $\begin{array}{l}\text { Permissive parent- } \\
\text { ing }\end{array}$ & & 0.613 & 0.037 & $0.226,0.371$ & 0.000 \\
\hline $\begin{array}{l}\text { Authoritarian par- } \\
\text { enting }\end{array}$ & & 0.184 & 0.051 & $-0.015,0.187$ & 0.094 \\
\hline $\begin{array}{l}\text { Authoritative par- } \\
\text { enting }\end{array}$ & & 0.059 & 0.049 & $-0.070,0.126$ & 0.575 \\
\hline Self as context & 0.554 & & & & \\
\hline $\begin{array}{l}\text { Permissive parent- } \\
\text { ing }\end{array}$ & & 0.345 & 0.034 & $0.093,0.228$ & 0.000 \\
\hline $\begin{array}{l}\text { Authoritarian par- } \\
\text { enting }\end{array}$ & & 0.171 & 0.047 & $-0.018,0.170$ & 0.110 \\
\hline $\begin{array}{l}\text { Authoritative par- } \\
\text { enting }\end{array}$ & & 0.423 & 0.046 & $0.098,0.281$ & 0.000 \\
\hline Defusion & 0.472 & & & & \\
\hline $\begin{array}{l}\text { Permissive parent- } \\
\text { ing }\end{array}$ & & 0.267 & 0.041 & $0.057,0.222$ & 0.001 \\
\hline $\begin{array}{l}\text { Authoritarian par- } \\
\text { enting }\end{array}$ & & 0.172 & 0.058 & $-0.028,0.200$ & 0.138 \\
\hline $\begin{array}{l}\text { Authoritative par- } \\
\text { enting }\end{array}$ & & 0.415 & 0.056 & $0.097,0.320$ & 0.000 \\
\hline Values & 0.467 & & & & \\
\hline $\begin{array}{l}\text { Permissive parent- } \\
\text { ing }\end{array}$ & & 0.644 & 0.043 & $0.263, .435$ & 0.000 \\
\hline $\begin{array}{l}\text { Authoritarian par- } \\
\text { enting }\end{array}$ & & -0.023 & 0.060 & $-0.131,0.107$ & 0.840 \\
\hline $\begin{array}{l}\text { Authoritative par- } \\
\text { enting }\end{array}$ & & 0.140 & 0.059 & $-0.043,0.189$ & 0.215 \\
\hline Committed actions & 0.240 & & & & \\
\hline $\begin{array}{l}\text { Permissive parent- } \\
\text { ing }\end{array}$ & & 0.418 & 0.060 & $0.144,0.382$ & 0.000 \\
\hline $\begin{array}{l}\text { Authoritarian par- } \\
\text { enting }\end{array}$ & & 0.236 & 0.083 & $-0.023,0.307$ & 0.091 \\
\hline $\begin{array}{l}\text { Authoritative par- } \\
\text { enting }\end{array}$ & & -0.143 & 0.081 & $-0.247,0.074$ & 0.287 \\
\hline
\end{tabular}

$N=100$
Table 5 Moderating Effect of gender on the Relationship between Parenting styles and Psychological flexibility in Adolescents $(\mathrm{N}=100)$

\begin{tabular}{llll}
\hline Predictors & \multicolumn{3}{l}{ Psychological flexibility } \\
\cline { 2 - 4 } & & \multicolumn{2}{l}{$95 \% C I$} \\
\cline { 2 - 4 } & $B$ & $L L$ & $U L$ \\
\hline Constant & $-120.18^{* * *}$ & -145.99 & -94.37 \\
Parenting styles & $2.37^{* * *}$ & 2.08 & 2.65 \\
Gender & $120.62^{* * *}$ & 99.79 & 141.44 \\
Parenting styles $\times$ Gender & $-1.37^{* * *}$ & -1.60 & -1.14 \\
$R^{2}$ & 0.82 & & \\
$\Delta R^{2}$ & 0.25 & & \\
$F$ & $148.69^{* * *}$ & & \\
$\Delta F$ & 137.59 & & \\
\hline
\end{tabular}

Table shows that gender moderates the relationship between parenting styles and psychological flexibility in adolescents. The interaction term of Parenting styles and gender significantly moderates this relationship $(\beta=-1.37, p<.05)$

$C I$ confidence interval, $U L$ upper limit, $L L$ lower limit

$* * * p<.001$

\section{Moderating Effect of Gender on Parenting and Psychological Flexibility}

Moderating effect of gender on the association between these two variables was investigated. The result indicated that gender moderates the association between parenting styles and psychological flexibility in adolescents. The interaction term of parenting styles and gender significantly moderates this relationship $(\beta=-1.37, p<0.05)$ (see Table 5).

\section{Gender Differences in Parenting and Psychological Flexibility}

The multivariate analysis (MANOVA) was applied to inspect whether the male and female adolescents differ on parenting styles and psychological flexibility. Initial postulation testing was performed to calculate the linearity, normality, univariate and multivariate outliers, with no serious desecrations, noted. We completed Wilks' Lambda test which showed non-significant. Results $=0.928, F(9,90)=0.77, p>0.05$, indicating that male and female adolescents have a similar parenting style and psychological flexibility (see Table 6).

\section{Discussion}

This study examined the impact of parenting styles on psychological flexibility among adolescents of Pakistan. Consistent with the proposed hypothesis, parenting styles significantly predicted psychological flexibility in this study. 
Table 6 Gender comparisons of parenting styles and psychological flexibility among male and female adolescents

\begin{tabular}{|c|c|c|c|c|c|c|c|}
\hline \multirow[t]{2}{*}{ Variables } & \multicolumn{2}{|c|}{ Male $(\mathrm{n}=50)$} & \multicolumn{2}{|c|}{ Female $(n=50)$} & \multirow[t]{2}{*}{$\mathrm{F}$} & \multirow[t]{2}{*}{$p$} & \multirow[t]{2}{*}{$\eta^{2}$} \\
\hline & $\mathrm{M}$ & SD & $\mathrm{M}$ & $\mathrm{SD}$ & & & \\
\hline Parenting styles & 89.88 & 21.437 & 88.76 & 9.667 & 0.113 & 0.737 & 0.001 \\
\hline Permissive parenting & 30.14 & 8.347 & 29.20 & 4.562 & 0.488 & 0.486 & 0.005 \\
\hline Authoritarian parenting & 30.10 & 7.215 & 29.70 & 6.867 & 0.081 & 0.777 & 0.001 \\
\hline Authoritative parenting & 29.64 & 8.542 & 29.86 & 4.998 & 0.025 & 0.875 & 0.000 \\
\hline Psychological flexibility & 90.12 & 21.664 & 87.98 & 10.145 & 0.400 & 0.528 & 0.004 \\
\hline Self-acceptance & 15.00 & 3.974 & 14.00 & 3.117 & 1.960 & 0.165 & 0.020 \\
\hline Present moment awareness & 15.12 & 3.783 & 15.02 & 2.699 & 0.023 & 0.879 & 0.000 \\
\hline Self as context & 14.98 & 3.815 & 14.50 & 2.243 & 0.588 & 0.445 & 0.006 \\
\hline Defusion & 14.90 & 3.721 & 14.58 & 3.296 & 0.207 & 0.650 & 0.002 \\
\hline Values & 15.00 & 3.974 & 15.02 & 3.304 & 0.001 & 0.978 & 0.000 \\
\hline Committed actions & 15.12 & 3.783 & 14.86 & 4.638 & 0.094 & 0.759 & 0.001 \\
\hline \multicolumn{8}{|l|}{$N=100$} \\
\hline \multicolumn{8}{|c|}{ MANOVA multivariate analysis of variance; $M$ Mean, $S D$ Standard Deviation, $p$ significance } \\
\hline \multicolumn{8}{|l|}{$* * p<.01$} \\
\hline$* * * p<.001$ & & & & & & & \\
\hline
\end{tabular}

Parenting styles such as permissive, authoritarian, and authoritative were significantly associated with psychological flexibility. Moreover, it was found that gender moderates the association between these variables. However, inconsistent with our hypothesis, gender differences in parenting patterns and psychological flexibility were non-significant. Additionally, it was found that parenting styles have strong relevance for psychological flexibility in adolescent samples.

Furthermore, results indicated that the permissive parenting style significantly predicted acceptance, present moment, self as content, defusion, values, committed actions subscale of psychological flexibility among the adolescent sample, indicating that adolescents of permissive parents have better emotional regulation and values due to parental cooperative, understanding and warmth behavior. Moreover, authoritarian parenting style predicted acceptance subscale of psychological flexibility. It could be due to higher expectations, demands and strictness of the parents, which are acceptable in Pakistani culture due to societal norms. The authoritative parenting style also significantly predicted psychological flexibility such as self as content, and defusion among the adolescent sample. It could be because parents' attitudes and practices have a direct influence on adolescents. These results are in line with existent literature, which reported that adolescents with the authoritative parents seems to be more famous, empathetic and socially acceptable (Sahithya et al., 2019; Steinberg et al., 1994). Contrary, adolescents who recognize their parents as controlling and aggressive are more likely to indulge in criminal behavior, have poor social skills (Brand et al., 2009; McElhaney \& Allen, 2001) and lower psychological flexibility.

Psychological flexibility supports the individual in embracing the aversive emotional situations (Hayes et al.,
2006). The psychological flexibility model is equally applicable to the functioning of adolescents as well as their parents (Greco \& Hayes, 2008). Awareness and acceptance of the emotional experience influence mental health and decreased psychopathologies (Ciarrochi et al., 2011) such as depression (Hayes et al., 2011) and anxiety (Semple et al., 2005). Positive parenting have good impacts on adolescent's social and communication skills (Betts et al., 2013), and supports interpersonal ties such as close relationships (Drózdz \& Pokorski, 2007). In conclusion, authoritative parenting, and family connections have been related to the increased level of optimism and hope among adolescents and children (Holder \& Coleman, 2009). Authoritativeness also appears to influence the optimism which moderates self-esteem, parenting, and psychopathologies such as depression, (Jackson, Pratt \& Pancer, 2005).

Additionally, it was also found that gender moderates the association between understudied variables. Interaction effects of moderation show that psychological flexibility in boys increases with more parental authority, while psychological flexibility in girls decreases with increasing parental authority. The possible explanation could be that boys are given more autonomy in their decisions but when parents keep control of their activities and guide them about different life situations, they become psychologically more flexible. Girls are overprotected, dependent and are not supposed to decide for the career, marriage, and work in Asian cultures due to higher parental control. Consequently, their psychological flexibility decreases with increasing parental authority.

Regarding the gender differences no gender differences were observed in different styles of parenting and psychological flexibility among girls' and boys' adolescents. Our 
findings are not in line with the Azevedo and Matos's (2015) study, who reported that male adolescents have higher psychological flexibility than female adolescents. Considering the importance and complex role of psychological flexibility in health, it was assumed that psychological flexibility is likewise important for both boys and girls and protect them from mental health issues (Azevedo \& Matos, 2015). Results indicate that parents equally invest their time, energies, and resources to treat their offspring regardless of their gender, as a result, they develop the same level of psychological flexibility. Moreover, during this stage, patterns of psychological functioning are not very rigid. One possible explanation could be that it is possibly due to growing interest of boys and girls in education, career approaches, therefore, they need equal attention of their parents, in turn, parents provide them all those resources and means which they required for their optimal development and progress.

The present study has diverse implications for mental health professionals, educationists and social workers who can contribute significantly to the psychological wellbeing of adolescents by educating appropriate parenting. Policymakers should develop policies to address poor psychological wellbeing and increased psychological distress in the context of family. The outcome of the study indicates that a program for adolescents may also include skills for parents aimed at improving their parenting styles as well as psychological flexibility, as parents will learn about adaptive parenting styles. Thus, the outcome of the current study supports the advantages of adaptive parenting styles which leads to higher psychological flexibility and lower psychological issues (Brassell, 2016).

The present study holds a great significance in terms of culture. In Pakistan, priority is given to family and society over the individualistic needs. Moreover, parents are fully responsible for the rearing and training their children. Daughters are closely supervised and cared till their marriage as compared to sons. Obedience is much valued in Pakistani culture and acceptance for dominance and control is more likely to be greater. Apart from social and cultural factors, religion has a major influence on the parenting practices; parents are given a status of 'second only to God' leading to compliance, respect and obedience to authority are encouraged. Hence, parental supervision and control is considered acceptable in Pakistan. This explains the positive relationship between authoritarian parenting style and the composite Psychological Flexibility score in Pakistani adolescents. Therefore, this study contributed significantly in understanding that how psychological flexibility of children can be influenced form parenting styles in Pakistani cultures.

The current study also has some limitations. Firstly, a small sample collected from a few cities of Pakistan could limit the generalization of study findings. Secondly, the cross-sectional research design raises the issue of causality of effects, which are addressed by a longitudinal research design. Future studies investigating a similar hypothesis should employ longitudinal research plan to examine long term effects. Thirdly, self-report measures were used which could lead to biased responses. Fourthly, regardless of the association of psychological flexibility with psychopathologies such as depression, anxiety (Fischer et al., 2016) and other health issues, we did not measure these psychological constructs which could confirm the findings of our study. Moreover, we also did not measure the psychological flexibility of parents, which could also influence their parenting styles and children's psychological flexibility (William, Ciarrochi, \& Heaven, 2012). So, we recommend that future studies should include these measures assessing internalizing, externalizing, and health issues of adolescents.

Funding Open Access funding enabled and organized by Projekt DEAL.

Data Availability The datasets generated during and/or analyzed during the current study are available from the corresponding author on reasonable request.

\section{Declarations}

Conflict of interest The authors declare that they have no competing interests.

Open Access This article is licensed under a Creative Commons Attribution 4.0 International License, which permits use, sharing, adaptation, distribution and reproduction in any medium or format, as long as you give appropriate credit to the original author(s) and the source, provide a link to the Creative Commons licence, and indicate if changes were made. The images or other third party material in this article are included in the article's Creative Commons licence, unless indicated otherwise in a credit line to the material. If material is not included in the article's Creative Commons licence and your intended use is not permitted by statutory regulation or exceeds the permitted use, you will need to obtain permission directly from the copyright holder. To view a copy of this licence, visit http://creativecommons.org/licenses/by/4.0/.

\section{References}

Alegre, A. (2011). Parenting styles and children's emotional intelligence: What do we know? The Family Journal, 19(1), 56-62.

Azevedo, A., \& Matos, A. P. (2015). Psychological Flexibility and Self-Compassion: Contributions of gender and its association with adolescent depression. Journal of Global Academic Institute Education \& Social Sciences, 1(2), 95-109.

Barnhart, C. M., Raval, V. V., Jansari, A., \& Raval, P. H. (2013). Perceptions of parenting style among college students in India and the United States. Journal of Child and Family Studies, 22(5), 684-693.

Barros, L., Goes, A. R., \& Pereira, A. I. (2015). Parental self-regulation, emotional regulation and temperament: Implications for intervention. Estudos de Psicologia (Campinas), 32(2), 295-306. 
Baumrind, D. (1991). The influence of parenting style of adolescent competence and substance use. Journal of Early Adolescence, 11(1), 56-95.

Baumrind, D. (1971). Current patterns of parental authority. Developmental Psychology, 4(1p2), 1-103.

Betts, L. R., Trueman, M., Chiverton, L., Stanbridge, A., \& Stephens, J. (2013). Parental rearing style as a predictor of attachment and psychosocial adjustment during young adulthood. Journal of Social and Personal Relationships, 30(6), 675-693.

Bhattacharyya, P., \& Pradhan, R. K. (2015). Perceived paternal parenting style and proactive coping strategies of Indian adolescents. International Journal of Psychological Studies, 7(2), 180-194.

Bibi, A., Lin, M., Zhang, X. C., \& Margraf, J. (2020). Psychometric properties and measurement invariance of Depression, Anxiety and Stress Scales (DASS-21) across cultures. International Journal of Psychology, 55(6), 916-925.

Bibi, A., Blackwell, S. E., \& Margraf, J. (2019). Mental health, suicidal ideation, and experience of bullying among university students in Pakistan. Journal of Health Psychology,0(00) 1-12.

Bibi, A., Kalim, S., \& Khalid, M. A. (2018). Post-traumatic stress disorder and resilience among adult burn patients in Pakistan: a cross-sectional study. Burns \& Trauma, 6(1), 6-8.

Bond, F. W., \& Bunce, D. (2003). The role of acceptance and job control in mental health, job satisfaction, and work performance. Journal of Applied Psychology, 88(6), 1057-1067.

Brand, S., Hatzinger, M., Beck, J., \& Holsboer-Trachsler, E. (2009). Perceived parenting styles, personality traits and sleep patterns in adolescents. Journal of Adolescence, 32(5), 1189-1207.

Brassell, A. A., Rosenberg, E., Parent, J., Rough, J. N., Fondacaro, K., $\&$ Seehuus, M. (2016). Parent's psychological flexibility: Associations with parenting and child psychosocial well-being. Journal of Contextual Behavioral Science, 5(2), 111-120.

Buri, J. R. (1991). Parental Authority Questionnaire. Journal of Personality and Social Assessment, 57(1), 110-119.

Chan, T. \& Koo, A. (2011). Parenting style and youth outcomes in the UK. European Sociological Review,27(3), 385-399.

Chipman, S., Olsen, S. F., Klein, S., Hart, C. H., \& Robinson, C. C. (2000). Differences in retrospective perceptions of parenting of male and female inmates and non-inmates. Family Relations, 49(1), 5-11.

Ciarrochi, J., Kashdan, T. B., Leeson, P., Heaven, P., \& Jordan, C. (2011). On being aware and accepting: A one-year longitudinal study into adolescent well-being. Journal of Adolescence, 34(4), 695-703.

Coolahan, K., McWayne, C., Fantuzzo, J., \& Grim, S. (2002). Validation of a multidimensional assessment of parenting styles for low-income African-American families with preschool children. Early Childhood Research Quarterly, 17(3), 356-373.

Cribb, G., Moulds, M. L., \& Carter, S. (2006). Rumination and experiential avoidance in depression. Behavior Change, 23(3), 165-176.

Clark-Carter, D. (2018). Quantitative psychological research: The complete student's companion. Routledge.

Darling, N., \& Toyokawa, T. (1997). Construction and validation of the parenting style inventory II (PSI-II). Unpublished manuscript.

Darling, N., \& Steinberg, L. (1993). Parenting style as context: An integrative model. Psychological Bulletin, 113(3), 487-496.

Davidov, M., \& Grusec, J. E. (2006). Untangling the links of parental responsiveness to distress and warmth to child outcomes. Child Development, 77(1), 44-58. https://doi.org/10.111 1/j.1467-8624.2006.00855.x

Drozdz, E., \& Pokorski, M. (2007). Parental attitudes and social competence in adolescents. Journal of Physiology and Pharmacology, 58(5), 175-184.

Fischer, T. D., Smout, M. F., \& Delfabbro, P. H. (2016). The relationship between psychological flexibility, early maladaptive schemas, perceived parenting and psychopathology. Journal of Contextual Behavioral Science, 5(3), 169-177.

Fledderus, M., Bohlmeijer, E. T., Smit, F., \& Westerhof, G. J. (2010). Mental health promotion as a new goal in public mental health care: A randomized controlled trial of an intervention enhancing psychological flexibility. American Journal of Public Health, 100(12), 2372-2378.

Flujas-Contreras, J. M., \& Gómez, I. (2018). Improving flexible parenting with acceptance and commitment therapy: A case study. Journal of Contextual Behavioral Science, 8, 29-35.

Greco, L. A., \& Hayes, S. C. (Eds.). (2008). Acceptance \& mindfulness treatments for children \& adolescents: A practitioner's guide. New Harbinger Publications.

Gugliandolo, M. C., Costa, S., Cuzzocrea, F., \& Larcan, R. (2014). Traitemotional intelligence as mediator between psychological control and behaviour problems. Journal of Child and Family Studies, 24(8), 1-11.

Haugstvedt, A., Wentzel-Larsen, T., Rokne, B., \& Graue, M. (2011). Perceived family burden and emotional distress: similarities and differences between mothers and fathers of children with type 1 diabetes in a population-based study. Pediatric diabetes, 12(2), $107-114$.

Hayes, S. C., Luoma, J. B., Bond, F. W., Masuda, A., \& Lillis, J. (2006). Acceptance and commitment therapy: Model, processes and outcomes. Behaviour Research and Therapy, 44(1), 1-25.

Hayes, S. C., Strosahl, K. D., \& Wilson, K. G. (2011). Acceptance and commitment therapy: The process and practice of mindful change (2nd ed.). Guilford Press.

Heaven, P., \& Ciarrochi, J. (2008). Parental styles, gender and the development of hope and self-esteem. European Journal of Personality, 22(8), 707-724.

Holder, M. D., \& Coleman, B. (2009). The contribution of social relationships to children's happiness. Journal of Happiness Studies, 10(3), 329-349.

Huver, R. M., Engels, R. C., Breukelen, G. V., \& Vries, H. D. (2007). Parenting style and adolescent smoking cognitions and behaviour. Psychology and Health, 22(5), 575-593.

Jackson, L., Pratt, M. \& Pancer, S. (2005). Optimism as a mediator of the relation between perceived parental authoritativeness and adjustment among adolescents: Finding the sunny side of the street. Social Development,14(2), 273-304.

Kashdan, T. B., \& Rottenberg, J. (2010). Psychological flexibility as a fundamental aspect of health. Clinical Psychology Review, 30(7), 865-878. https://doi.org/10.1016/j.cpr.2010.03.001

Kashdan, T. B., Barrios, V., Forsyth, J. P., \& Steger, M. F. (2006). Experiential avoidance as a generalized psychological vulnerability: Comparisons with coping and emotion regulation strategies. Behaviour research and therapy, 44(9), 1301-1320.

Keller, H., \& Otto, H. (2009). The cultural socialization of emotion regulation during infancy. Journal of cross-cultural psychology, 40(6), 996-1011.

Laible, D. J., \& Carlo, G. (2004). The differential relations of maternal and paternal support and control to adolescent social competence, self-worth, and sympathy. Journal of Adolescent Research, 19(6), 759-782.

Landstra, J. M., Ciarrochi, J., Deane, F. P., \& Hillman, R. J. (2013). Identifying and describing feelings and psychological flexibility predict mental health in men with HIV. British Journal of Health Psychology, 18(4), 844-857.

Lee, J. K., Orsillo, S. M., Roemer, L., \& Allen, L. B. (2010). Distress and avoidance in generalized anxiety disorder: Exploring the relationships with intolerance of uncertainty and worry. Cognitive Behavior Therapy, 39(2), 126-136.

Liem, J. H., Cavell, E. C., \& Lustig, K. (2010). The influence of authoritative parenting during adolescence on depressive symptoms in young adulthood: Examining the mediating roles of 
self-development and peer support. The Journal of Genetic Psychology, 171(1), 73-92.

McElhaney, K. B., \& Allen, J. P. (2001). Autonomy and adolescent social functioning: The moderating effect of risk. Child Development, 72(1), 220-231.

Milevsky, A., Schlechter, M., \& Netter, S. (2007). Maternal and paternalparenting styles in adolescents: Associations with selfesteem, depression and life-satisfaction. Journal of Child and Family Studies, 16(1), 39-47.

Moilanen, K. L., Shaw, D. S., \& Fitzpatrick, A. (2010). Self-regulation in early adolescence: Relations with mother-son relationship quality and maternal regulatory support and antagonism. Journal of Youth and Adolescence, 39(11), 1357-1367.

Moyer, D. N., \& Sandoz, E. K. (2015). The role of psychological flexibility in the relationship between parent and adolescent distress. Journal of Child and Family Studies, 24(5), 1406-1418.

Padilla-Walker, L. M., Day, R. D., Dyer, W. J., \& Black, B. C. (2013). “Keep on keeping on, even when it's hard!” Predictors and outcomes of adolescent persistence. The Journal of Early Adolescence, 33(4), 433-457.

Rodriguez, C. M. (2003). Parental discipline and abuse potential effects on child depression, anxiety, and attributions. Journal of Marriage and Family, 65(4), 809-817.

Rolffs, J. L., Rogge, R. D., \& Wilson, K. G. (2016). Disentangling Components of Flexibility via the Hexaflex Model Development and Validation of the Multidimensional Psychological Flexibility Inventory (MPFI). Assessment, 25(4), 458-482.

Rolffs, J. L., Rogge, R. D., \& Wilson, K. G. (2018). Disentangling components of flexibility via the hexaflex model: Development and validation of the Multidimensional Psychological Flexibility Inventory (MPFI). Assessment, 25(4), 458-482.

Sahithya, B. R., Manohari, S. M., \& Vijaya, R. (2019). Parenting styles and its impact on children-a cross cultural review with a focus on India. Mental Health, Religion \& Culture, 22(4), $357-383$
Semple, R. J., Reid, E. F. G., \& Miller, L. (2005). Treating anxiety with mindfulness: An open trial of mindfulness training for anxious children. Journal of Cognitive Psychotherapy, 19(4), 379-392.

Sloan, D. M. (2004). Emotion regulation in action: Emotional reactivity in experiential avoidance. Behaviour Research and Therapy, 42(11), 1257-1270.

Steinberg, L., Lamborn, S., Darling, N., Mounts, N., \& Dornbusch, S. (1994). Over-time changes in adjustment and competence among adolescents from authoritative, authoritarian, indulgent, and neglectful families. Child Development, 65(3), 754-770.

Thergaonkar, N. R., \& Wadkar, A. J. (2007). Relationship between Test Anxiety and Parenting Style. Journal of Indian Association for Child and Adolescent Mental Health, 3(1), 10-12.

Trivers, R. L., \& Willard, D. E. (1973). Natural selection of parental ability to vary the sex ratio of offspring. Science, 179(4068), 90-92.

Tull, M. T., Gratz, K. L., Salters, K., \& Roemer, L. (2004). The role of experiential avoidance in posttraumatic stress symptoms and symptoms of depression, anxiety, and somatization. The Journal of Nervous and Mental Disease, 192(11), 754-761.

Williams, K. E., Ciarrochi, J., \& Heaven, P. C. (2012). Inflexible parents, inflexible kids: A 6-year longitudinal study of parenting style and the development of psychological flexibility in adolescents. Journal of Youth and Adolescence, 41(8), 1053-1066.

Wright, M. F. (2016). Bullying among adolescents in residential programs and in public school: the role of individual and contextual predictors. Journal of Aggression, Conflict and Peace Research, $8(2), 86-98$.

Publisher's Note Springer Nature remains neutral with regard to jurisdictional claims in published maps and institutional affiliations. 